\title{
THE AGILE PROJECT MANAGEMENT UNDERPINNINGS: BACKLOG REFINEMENT, TEAM COMPOSITION, AND BACKLOG PREPARATION
}

\author{
Rosarito Sánchez-Morcilio, University of Puerto Rico, Río Piedras Campus, rosarito.sanchez@upr.edu \\ Francisco Quiles-Torres, University of Puerto Rico, Río Piedras Campus, francisco.quiles@upr.edu
}

\begin{abstract}
There are numerous publications about agile techniques in project management. Notwithstanding, there are questions regarding what is essential in agile and the proper manner of pursuing it. The objectives of this study are to find the underpinnings of agile project management and to evaluate the approach organizations accomplish those underpinnings. We propose the agile project management underpinnings: Backlog Refinement, Team Composition, and Backlog Preparation, as a strategy to successfully manage projects based on its relationship to agile best practices, and how organizations implement those in their projects.
\end{abstract}

Keywords: Agile Project Management underpinnings, Project Management, agile in organizations, agile

\section{INTRODUCTION}

Often the need for new technology to improve industry practices catalyzes new inventions. Innovative projects are not traditional and predictable; its project manager must deal with uncertainties, high risks, and complexities. The Shed (2019) is one example of what an innovative project is. Agile practices in project management offer solutions to address groundbreaking endeavors beyond just software development. In a sea of information about agile methods, this article emphasizes the Agile Project Management (APM) underpinnings, which are the best practices, and how organizations adopt those underpinnings into their projects. Its applications are suitable for all types of industries.

\section{Justification for the study}

There is a need to study agile project management and its relationship with agile best practices to be able to understand and apply its principles into innovation-related projects. This article guides the reader into the essential APM techniques, helping project managers to make informed decisions about the application of APM tools in their companies. Next, it serves as a guide for project manager practitioners who want or need to get up to speed with the tools used on agile projects, as well as for future project managers to be capable of handling projects under the current fast-paced business environment. Lastly, the article provides academia with details associated with the latest trends in this field to align academic research with the needs of the industry. The article offers background on agile practices, the research methodology employed for the study, its findings, and the discussion of the results. Lastly, the conclusions embrace the limitations of the study, as well as directions for future research.

\section{Background}

Innovation in many instances occurs with the use of technology because it transforms the operations of any industry (construction, legal, banking, insurance, and software development), aiming to add value to the business. Project management knowledge and practices are crucial to embrace that transformation. Uncertainties in achieving the scope is a common characteristic of projects where innovation is an essential aspect. Aligning the project drivers of a new system or product with the existing business drivers of an ongoing operation may represent a challenge as modern manufacturing or operational techniques may be required to achieve the project goal. The traditional project management charter expectation of having a fixed, pre-defined scope, cost, and time are problematic when dealing with uncertainty (Sánchez, Terlizzi, \& de Moraes, 2017, and Terlizzi, Albertin, \& de Moraes, 2017). The agile project management is specific in overseeing ambiguities since it is not focused on a fixed scope, but rather on delivering value. Independently of the project original scope, the constant deliverables revision employed under the agile methodology will eventually bring a value-added application, new product or an innovative strategy to the organization. APM is essential to accomplish added-value business products and applications effectively. It is fundamental to know if the supervision of a project is agile; otherwise, the project may not be taking the business added-value advantages that agile technique brings to make it a success. An essential definition in APM is a 
backlog, which consists of a list of customer satisfaction requirements in order of preference (Agile Practice Guide, 2017). A backlog is not a mini waterfall (where work completed is crossed out), but rather a register of possible ways to create business value through work out-performing requirements. Stories, which is a single and straightforward user necessity that would bring added value to the business (Agile Practice Guide, 2017) is a backlog.

The existing relevant literature found about the agile best practices is: Azanha, Argoud Terra, de Camargo Junior, \& Domingos Antoniolli (2017), Dennehy, \& Conboy (2018), Dingsøyr, Moe, Seim (2018), Hobbs, \& Petit (2017), Lappi, \& Aaltonen (2017), Lappi, Aaltonen, \& Kujala (2018), Moe, Dingsøyr, \& Rolland (2018), Sánchez-Vicente, Soler-Severino, \& García-Santos (2019), Sánchez, Terlizzi, \& de Moraes (2017), Terlizzi, Albertin, \& de Moraes (2017), Vahanvati, \& Mulligan (2017), and Vieira, Argoud, \& Antoniolli (2017). Although those articles explain how organizations implemented the APM underpinnings, those did not emphasize on the APG (2017) APM coverage. Some of the articles named the APG (2017) coverage with its element name, and the rest of the articles used other names that coincided with the APG (2017) coverage element description. Besides, each of those articles features in only one industry. In contrast to those articles, the study presented in this article discusses the APG (2017) APM underpinnings, highlighting on the agile best practices, and how organizations adopt those underpinnings into their projects. This study's results apply to all types of industries.

\section{RESEARCH METHODOLOGY}

This study was conducted using both qualitative and quantitative methodologies. There are two research objectives and one proposition. The first research objective is to find the underpinnings of APM. The second research objective is to evaluate how organizations implement APM underpinnings. The proposition illustrates the use of APM underpinnings as a strategy to successfully manage projects.

\section{Research Objective 1 (RO 1): To find the underpinnings of APM.}

The methodologies to find the APM underpinnings are qualitative and quantitative.

\section{RO 1 Qualitative methodology}

As for the qualitative method, we use the Agile Practice Guide, APG (2017). The APG (2017) was developed by a diverse group of project managers, as a model to implement agile techniques into project management. The APG (2017) is an advocate of the Project Management Institute (2017), an international project management organization. The APG (2017) developed a map of their Agile Practice Coverage (APC) against another agile principle developed by a different group (Agile Manifesto, 2001). Both the Agile Practice Coverage (2017) and the Agile Manifesto Values, from the Agile Manifesto Principles (Agile Manifesto, 2001), dictates the best practices in conducting agile projects and are trustful because of its international amplitude. The list of the APG coverage is extensive, and its redundancy on many principles against the Agile Manifesto Principles demonstrates its relevance to agile project management.

\section{RO 1 Quantitative methodology}

Furthermore, this study was quantitative because we found out how many times the APG coverage repeated itself against the Agile Manifesto Principles. We sorted the APG coverage repetitions from largest to smallest discovering patterns; the redundancy of APG coverage demonstrates its significance on APM. The three most significant APG coverage constituted the APM underpinnings. For the inclusion criteria, we selected the three most repeated Agile Manifesto Mapping (Annex A2 of Agile Practice Guide, 2017) APG coverage in the sorted list. For the exclusion criteria, we did not select any other APG coverage from the Agile Manifesto Mapping (Agile Practice Guide, 2017) than the first three most repeated in the sorted list.

Research Objective 2 (RO 2): To evaluate how organizations implement the APM underpinnings.

The methodology used for researching this objective was qualitative and quantitative.

\section{RO 2 Qualitative methodology}




\section{Issues in Information Systems}

Volume 20, Issue 3, pp. 94-106, 2019

Initially, RO 2 was qualitative because we read and examine each of the cases presented in a selected number of articles focusing on the Agile Practice Guide (2017) APM underpinnings. Therefore, we conducted a data exploration aiming to organize it for its better understanding. Data analysis to discover how organizations implement APM underpinnings consisted of searching the RO 1 APM underpinnings, by its element name or by its element description in each of the cases exhibited in the chosen articles. In the instances when the APM underpinning element name did not show, we had to use the APM underpinning element description to find about its implementation. If neither the APM underpinning element name nor the APM underpinning element description appeared in the case described in the article, then we agreed that case did not implement the APM underpinning in question. If either the APM underpinning element name or its description emerged in the case outlined in the article, then we agreed to write a brief sentence explaining how that APM underpinning was implemented. This study is reliable because data analysis must focus on the Agile Practice Guide (2017) APM underpinning element name or its description for future studies to produce the same results. This study's data collection validity consists of exploring the selected articles according to the Agile Practice Guide (2017) APM underpinning element name or its description. We did not have a text analytical software tool to perform the RO 2 qualitative analysis activities.

For the qualitative inclusion criteria, we selected APM cases from various peer-reviewed journals: The Journal of Modern Project Management, International Journal of Managing Projects in Business, International Journal of Information Systems and Project Management, International Journal of Project Management, Iberoamerican Journal of Project Management, and Project Management Journal published between 2017 to 2019. We used these journals since our university's library system classified them as potential peer-reviewed sources. The search keywords to find the cases were "agile project management." The selection of cases focused on three main factors: 1) the description of a successful project; 2) the use of a case study on its methodology and 3) the cases involved an industry, including software.

For the qualitative exclusion criteria, we did not select peer-reviewed articles from other journals nor published before 2017 or after 2019. We excluded articles under the keywords "agile project management" in the selected journals on the proposed dates, that did not have the case study as its methodology.

\section{RO 2 Quantitative methodology}

The quantitative analysis consisted of organizing previous RO 2 qualitative data into a database. Once we had the database, we could analyze data strategically into different tables and charts to observe patterns of behavior that can lead to relevant findings. For the quantitative data analysis, we organized data in a structured way by using a database managed in Microsoft Access ${ }^{\circledR}$ (2018). The queries resulted from the database served as a backbone for further data exploration, such as data visualization "charts," which we created by using Power BI® (2019), and Microsoft Excel® (2018).

\section{FINDINGS}

The findings for RO 1: To find the underpinnings of $A P M$

We found 17 APG coverage mapped to the Agile Manifesto Values (Agile Manifesto, 2001) in the Annex A2 (Agile Practice Guide, 2017). After sorting the 17 APG coverage list, we found Backlog Refinement repeated five times, followed by Team Composition repeated four times. As for the third position in the list, we found four APG coverage, which is Backlog Preparation, Charter the Project and the Team, Execution Practices that help the Team Deliver Value, and Retrospectives. Figure 1 is a Funnel chart showing the sorted list by APG coverage to Agile Manifesto Values (Agile Practice Guide, 2017). Based on what we learned from reading the Agile Practice Guide (2017), we selected Backlog Preparation to be the third most crucial APG coverage on the list since it is closely related to Backlog Refinement, the first one in the list, and because it only occurs after a Backlog Preparation. The APM underpinnings are the three most redundant APG coverage, which is Backlog Refinement, Team Composition, and Backlog Preparation. 


\section{Issues in Information Systems}

Volume 20, Issue 3, pp. 94-106, 2019
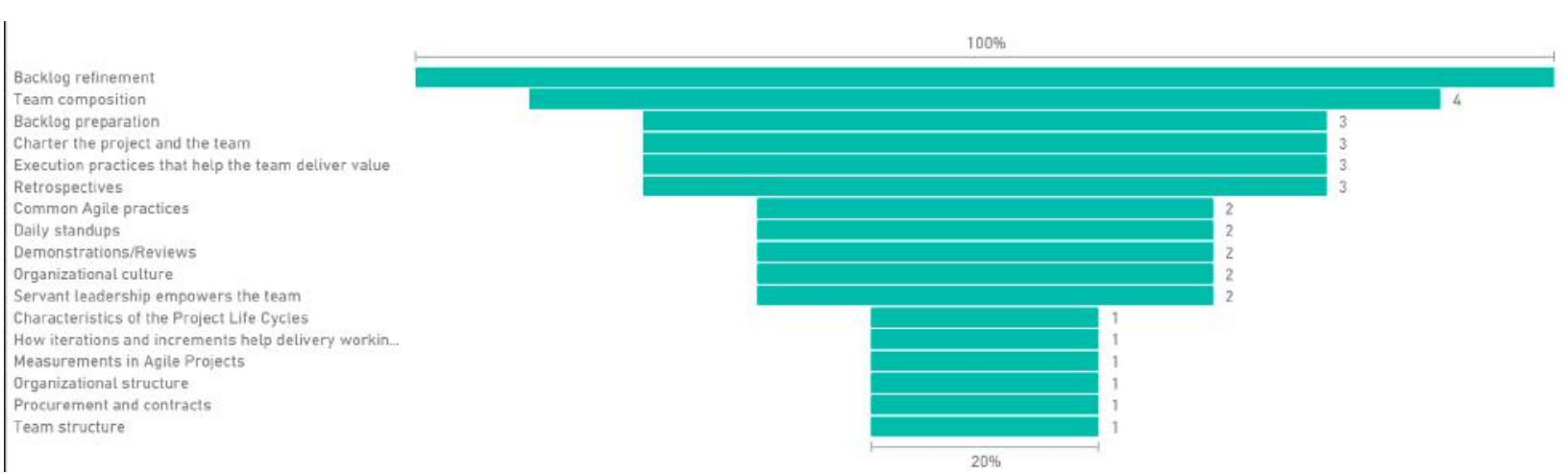

Figure 1. Funnel chart shows the sorted list by Agile Practice Guide (APG) coverage to Agile Manifesto Values (Agile

Practice Guide, 2017)

Table 1 shows the list of the three APG coverage that resulted in being the underpinnings of APM. The three APG coverage selected, as the APM underpinnings are Backlog Refinement, Team Composition, and Backlog Preparation. The next column in the figure shows the elements associated with those underpinnings, and the last column shows the element descriptions, both are according to the Agile Practice Guide (2017).

Table 1. The list of the three APG coverage, resulted as the underpinnings of APM, the elements associated to them along with its description (Agile Practice Guide, 2017)

\begin{tabular}{|c|c|c|}
\hline APGElementFullName & ElementName & ElementDescription \\
\hline Backlog refinement & discussions & about how work is complying with the story requirements \\
\hline Backlog refinement & problems & associated with the understanding of the stories \\
\hline Backlog refinement & value delivery & determine if work produced is contributing to business value \\
\hline Backlog refinement & spike & experiment the feature to understand its risks \\
\hline Backlog refinement & meeting & for the product owner to present ideas for the stories and for the team to learn about them and its potential challenges \\
\hline Backlog refinement & teedback & frequent and enough feedback to understand the story and product work results \\
\hline Backlog refinement & potential challenges & on how the ideas of the stories will be adopted \\
\hline Backlog refinement & timeboxed & one-hour discussion midway through two-week iteration how work produces is complying with the stories \\
\hline Backlog refinement & story ideas & product owner vision of what is needed \\
\hline Backlog refinement & card & take next card of the to-do list \\
\hline Backlog refinement & refinement of stories & to understand a new product, a product area, or a problem domain \\
\hline Backlog refinement & relationship between stories & work dependencies \\
\hline Team composition & product owner & responsible for guiding the direction of the work produced, while identifying its business value \\
\hline Team composition & servant leader & team facilitatitor who provides coaching and removes impediments for the team to work at the best capacity \\
\hline Team composition & cross-functional team member & team member has the necessary skills to complete the high-quality work in the shortest possible time and without external dependencies \\
\hline Backlog preparation & ordered list & all work in the story for the team is listed in sequence or priority \\
\hline Backlog preparation & replans & product owner replans the next iteration based on what the team produces \\
\hline Backlog preparation & roadmap & to show sequence or progression of deliverables over time \\
\hline Backlog preparation & enough work & to understand what is required and what would bring business value to that work \\
\hline Backlog preparation & business value & work is customer value focussed \\
\hline
\end{tabular}

As shown in Table 1, the Backlog Refinement is the first underpinning having 12 elements associated with it. The Backlog Refinement elements are discussions, problems, value delivery, spike, meeting, feedback, potential challenges, timeboxed, story ideas, card, refinement of stories, and the relationship between stories. The Team Composition is the second underpinning, having the servant leader or the team facilitator, the product owner, and the cross-functional team member associated with it. The Backlog Preparation is the third underpinning that has five elements related to it, ordered list, replants, roadmap, enough work, and business value. We found 12 articles that described successful cases of APM, which are Azanha, Argoud Terra, de Camargo Junior, \& Domingos Antoniolli (2017), Dennehy, \& Conboy (2018), Dingsøyr, Moe, Seim (2018), Hobbs, \& Petit (2017), Lappi, \& Aaltonen (2017), Lappi, Aaltonen, \& Kujala (2018), Moe, Dingsøyr, \& Rolland (2018), Sánchez-Vicente, Soler-Severino, \& García-Santos (2019), Sánchez, Terlizzi, \& de Moraes (2017), Terlizzi, Albertin, \& de Moraes (2017), Vahanvati, \& Mulligan (2017), and Vieira, Argoud, \& Antoniolli (2017). We examined the articles by focusing on the APM underpinnings, specifically its element descriptions. There were 20 elements, shown in Table 1. Each of the 12 article cases was assessed identifying the 20 elements and discovering the element implementation on the case, yielding a total of 240 items in a database. 


\section{Issues in Information Systems}

Volume 20, Issue 3, pp. 94-106, 2019

The findings for RO 2: To evaluate how organizations implement the APM underpinnings.

Table 2 shows the data employed to draw the Forest plot. From a total of 20 elements, we used 14 of those since six were outliers.

Table 2. Agile Project Management (APM) Underpinning (ElementFullName), the element name, and the number of instances the cases' authors described the elements.

\begin{tabular}{|c|c|c|c|c|c|}
\hline ElementFullName & ElementName & ElemDescribedInCase & e ElemNoDescInCase & Average & \\
\hline 1 Backlog Preparation & business value & 11 & -1 & 5 & \\
\hline 2 Backlog Refinement & card & 0 & -12 & -6 & outlier \\
\hline 3 Team Composition & cross-functional team member & 12 & 0 & 6 & outlier \\
\hline 4 Backlog Refinement & discussions & 7 & -5 & 1 & \\
\hline 5 Backlog Preparation & enough work & 11 & -1 & 5 & \\
\hline 6 Backlog Refinement & feedback & 8 & -4 & 2 & \\
\hline 7 Backlog Refinement & meeting & 10 & -2 & 4 & \\
\hline 8 Backlog Preparation & ordered list & 9 & -3 & 3 & \\
\hline 9 Backlog Refinement & potential challenges & 9 & -3 & 3 & \\
\hline 10 Backlog Refinement & problems & 10 & -2 & 4 & \\
\hline 11 Team Composition & product owner & 10 & -2 & 4 & \\
\hline 12 Backlog Refinement & refinement of stories & 6 & -6 & 0 & outlier \\
\hline 13 Backlog Refinement & relationship between stories & 6 & -6 & 0 & outlier \\
\hline 14 Backlog Preparation & replans & 3 & -9 & -3 & \\
\hline 15 Backlog Preparation & roadmap & 5 & -7 & -1 & \\
\hline 16 Team Composition & servant leader & 12 & 0 & 6 & outlier \\
\hline 17 Backlog Refinement & spike & 2 & -10 & -4 & \\
\hline 18 Backlog Refinement & story ideas & 7 & -5 & 1 & \\
\hline 19 Backlog Refinement & timeboxed & 0 & -12 & -6 & outlier \\
\hline \multirow[t]{6}{*}{20 Backlog Refinement } & value delivery & 9 & -3 & 3 & \\
\hline & Grand Total & 147 & -93 & 1.35 & \\
\hline & & & & & \\
\hline & Total Elements & 20 & & & \\
\hline & Total Outliers & 6 & & & \\
\hline & Total Elements for the plot & 14 & & & \\
\hline
\end{tabular}

Figure 2 shows the APM Underpinnings Forest plot. The X-axis indicates the number of element descriptions; its negative in that axis represents the lack of element descriptions. The Y-axis shows each of the selected elements along with its underpinning. To find significance among the underpinning elements, we observed where the location of the underpinning element descriptions average points. If the points vertically coincided, then we concluded that those underpinning elements were significant. The first black vertical line represents the zero from the X-axis. The second black vertical line over number two from the X-axis points out the first harmonization, where the authors coincided, including the Backlog Refinement discussions, and the Backlog Refinement story ideas. The third black vertical line over number three from the X-axis points out the second harmonization, where the authors coincided, including the Backlog Preparation ordered list, the Backlog Refinement potential challenges, and the Backlog Refinement value delivery. The fourth black vertical line over number four from the X-axis points out the third harmonization, where the authors coincided, including the Backlog Refinement meetings, Backlog Refinement problems, and the Team Composition product owner. The fifth black vertical line over number five from the X-axis points out the fourth harmonization, where the authors coincided, including the Backlog Preparation business value, and Backlog Preparation enough work. The Gran Total line is the average of all described and not described elements. The Gran Total average is 1.35 , and its standard deviation is 3.73. The diamond, the Gran Total average, signifies that most of the authors provided element descriptions. 


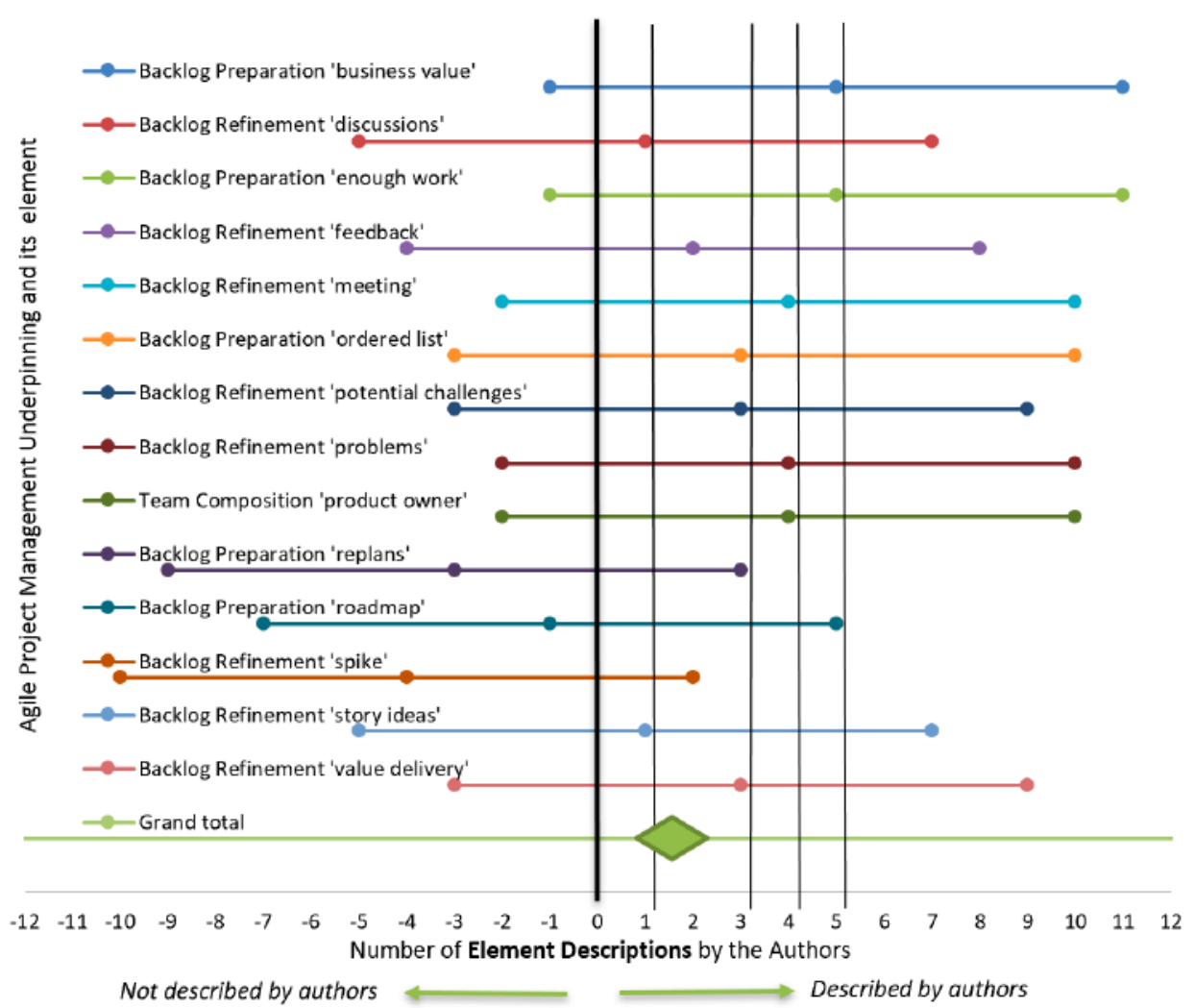

Figure 2. Agile Project Management (APM) Underpinnings Forest plot

\section{DISCUSSION}

The discussion for RO 1: To find the underpinnings of APM.

Many sources of information discuss APM, including Agile Practice Guide (2017). None of those sources focuses on the essence or the underpinnings of agile. This objective postulates the underpinnings of APM. We used the Annex A2 Agile Manifesto Mapping from the Agile Practice Guide (2017) to find the underpinnings of the APM because it assigns the APG coverage and title to each of the Agile Manifesto Values (Agile Manifesto, 2001). The appendix's purpose is to show the parallelism between the APG coverage and the foundation of agile methodology, the Agile Manifesto Values. We detected that the more APG coverage declaration in the appendix, the more relevancy it is in reinforcing the Agile Manifesto Value. We found Backlog Refinement repeated the most in the list, followed by Team Composition. As for the third position on the list, we had to choose one from four APG coverage. We selected Backlog Preparation since it is closely related to Backlog Refinement already in the first position. The APM underpinnings are Backlog Refinement, Team Composition, and Backlog Preparation. The rest of the APG coverage is significant, but it is not as relevant in determining the alignment of the project with the Agile Manifesto Principles (2001).

\section{Definitions for the APM underpinnings}

The Backlog Refinement refers to the meetings the team performs to discuss a fair amount of story improvements and its relationship with emphasis on value delivery. From those discussions, story ideas, potential challenges, and problems may arise. The cards guide the discussions since those contain what is next on the list of stories. The celebration of an hour every week team meetings are useful for feedback. Sometimes, the team creates an experimental sample to show the customers its results and possible value to the business. Table 1 has a list of the elements associated with the Backlog Refinement underpinning (Agile Practice Guide, 2017). The Team Composition has only three elements related to it, the product owner, the servant leader, and the cross-functional team. The product owner has business knowledge, and many times a technological background. This member guides the direction of the work priorities, explains the story ideas, tests the work performed by the cross-functional team, and organizes work aiming to create business value. Work that would add more business value 


\section{Issues in Information Systems \\ Volume 20, Issue 3, pp. 94-106, 2019}

will have precedence. The servant leader removes the impediments facilitating the work for the cross-functional team and knows the agile practices to coach the team in that direction. This member can be the project manager, the Scrum master, the project team lead, the team coach or the team facilitator. The better the servant leader knows the client's organizational culture, the more effective the project will result. The cross-functional teams organize themselves according to their technological knowledge. They have the skills necessary to complete the work on the shortest time. They are the designers, testers, and developers and do not have a list of tasks to complete mechanically complying with all the requirements. Instead, they concentrate on delivering a smaller number of features that add value to the business. That team has the empowerment to provide problem-solving while enhancing productivity (Agile Practice Guide, 2017). The Backlog Preparation refers to a well-organized registry of the work an adequate number of the stories involves. The team has this registry to understand the expected work. A sequence of deliverables over time shows the team the priority work that would add value to the business. Sometimes, a change of plans directs work based on the production of work by the team. Table 1 shows the list of the five elements associated with the Backlog Preparation underpinning (Agile Practice Guide, 2017).

\section{The discussion for RO 2: To evaluate how organizations implement the APM underpinnings.}

For this research objective, we learned about agile implementation in organizations as the authors' cases provided the underpinning's element descriptions. If the authors described the underpinning elements, which means that the organization is implementing it. Table 3 shows the list of authors' cases, the country, the industry, as well as the agile method. It is important to distinguish between the Sánchez, Terlizzi, \& de Moraes (2017) and the Terlizzi, Albertin, \& de Moraes (2017) articles. The Sánchez, Terlizzi, \& de Moraes (2017) is about cost and time project success from a leading bank in Brazil, and the Terlizzi, Albertin, \& de Moraes (2017) is about the experience of four Brazilian financial institutions.

Table 3. List of the authors' articles, with country, industry, and agile method described in the case

\begin{tabular}{|r|l|l|l|}
\hline AuthorsID & AuthorsLastNamesYearPar & AuthorsCaseCountry & AuthorsCaseIndustry \\
\hline 1 & (Azanha, Argoud Terra, de Camargo Junior, \& Domingos Antoniolli, 2017) & Brazil & AgileMethod \\
\hline 2 & (Dennehy, \& Conboy, 2018) & Ireland & Technology solutions \\
\hline 3 & (Dingsøyr, Moe, Seim, 2018) & Norway & Flow \\
\hline 4 & (Lappi, Aaltonen, \& Kujala, 2018) & Finland & Financial Insurance \\
\hline 5 & (Moe, Dingsøyr, \& Rolland, 2018) & Norway & International consulting \\
\hline 6 & (Hobbs, \& Petit, 2017) & Canada & PRINCE2 \\
\hline 7 & (Lappi, \& Aaltonen, 2017) & Finland & Financial Organizations \\
\hline 8 & (Sánchez, Terlizzi, \& de Moraes, 2017) & Scrum \\
\hline 9 & (Terlizzi, Albertin, \& de Moraes, 2017) & Brazil & Financial Banking \\
\hline 10 & (Vahanvati, \& Mulligan, 2017) & Brazil & Financial Institutions \\
\hline 11 & (Vieira, Argoud, \& Antoniolli, 2017) & India & Scrum \\
\hline 12 & (Sánchez-Vicente, Soler-Severino, \& García-Santos, 2019) & Brazil & Construction Housing \\
\hline & & Florida, United States & Construction Retail \\
\hline
\end{tabular}

Table 2 shows the 20 underpinning elements, and the six were outliers. Fourteen were the underpinning elements used to plot the Forest chart. Figure 2 shows the Forest plot. It shows that only six of the underpinning elements were significant. Those significant underpinning elements are Backlog Refinement discussions, Backlog Refinement story ideas, Backlog Preparation ordered list, Backlog Refinement potential challenges, Backlog Refinement value delivery, Backlog Refinement meetings, Backlog Refinement problems, Team Composition product owner, Backlog Preparation business value, Backlog Preparation enough work. The diamond in the Gran Total line from Figure 2 implies that most of the cases studied the use the APM underpinnings' elements in the cases since the authors provided its element descriptions. The fact that the diamond is over zero suggests that the organizations are starting to implement those elements into their project management practices. If the diamond were farther from zero, that is more element descriptions from the authors, which would have signified that agile methods are more mature because many organizations are using them.

\section{The authors' cases APM implementation}

Data exploration to discover how organizations implement APM underpinnings consisted of searching the RO 1 APM underpinnings elements in each case. To ensure the reliability and the validity of the study, table 1 shows the list of the three APM underpinning element names from the APG coverage (Agile Practice Guide, 2017), along with its description.

The underpinning's element descriptions in the cases provide relevant lessons for managers to take into consideration for the successful agile implementation in their projects. This section discusses how the organizations represented in the authors' cases implement the APM underpinnings, as discovered by the Figure 2 Forest plot. The organizations described in the cases are from different industries belonging to a wide range of countries. First, there is the underpinning before the element name. 


\section{Issues in Information Systems \\ Volume 20, Issue 3, pp. 94-106, 2019}

Second, we discuss the description of the element from the Agile Practice Guide (2017) briefly. Third, the way the authors' cases implement the APM underpinnings follows.

\section{Backlog Preparation business value}

The work is customer value focused (Agile Practice Guide, 2017). The primary issue was understanding customer value, the result was a project completed in five (5) months, on time, and budget, with customer satisfaction, and value added to the business (Azanha, Argoud Terra, de Camargo Junior, \& Domingos Antoniolli, 2017). Business requirements often change with customer involvement, but a high-value product was released (Dennehy, \& Conboy, 2018). The non-financial incentives motivated the team in achieving the value delivery. The acceptance criteria were the value creation of the solutions by using technology for innovation to digital government enhancing its relationship with the citizens (Lappi, Aaltonen, \& Kujala, 2018). The celebration of regular meetings allowed for business value achievement of releases (Moe, Dingsøyr, \& Rolland, 2018). When the emphasis is on customer value, there are many questions regarding the different agreements in the Agile environment (Hobbs, \& Petit, 2017). The utilization of two (2) product owners, one for the business requirement, and another one for the Information and Communication Technology did not improve business value (Lappi, \& Aaltonen, 2017). Information systems projects are of strategic importance to the organization. Its focus is not just controlling cost, time, and scope, but its emphasis is in how much Information Systems projects results add value to the organization (Sánchez, Terlizzi, \& de Moraes, 2017). A list of benefits or business value in the business case is key to better monitor projects (Terlizzi, Albertin, \& de Moraes, 2017). The socio-cultural enrichment was the reason for providing various material and technology choices, adding value to the business (Vahanvati, \& Mulligan, 2017). The user confirmed and checked all the processes of the project, adding value to the company (Vieira, Argoud, \& Antoniolli, 2017). The quality of deliverables was a high-level requirement and determined the speed of work from the team (Sánchez-Vicente, SolerSeverino, \& García-Santos, 2019).

\section{Backlog Preparation enough work}

Enough work refers to understanding the requirements that would value to the business (Agile Practice Guide, 2017). Labor aims to create a vision of the product, on a fix time duration, one to four weeks (Azanha et al., 2017). Difficulty predicting the time it takes for a complete value-added work, since measuring quality is challenging (Dennehy, \& Conboy, 2018). Epics described work (Dingsøyr, Moe, Seim, 2018). Start doing, instead of writing everything down (Lappi, Aaltonen, \& Kujala, 2018). The verification of work was according to the expectations of the rest of the team and the clients (Moe, Dingsøyr, \& Rolland, 2018). The teams, committees, and individual members played critical roles in the coordination of the work of the development teams, and the technical excellence of the respective areas of specialization (Hobbs, \& Petit, 2017). The Scrum master and the product owner were crucial in agile methods to assure business value in work performed (Lappi, \& Aaltonen, 2017). The outsource index is the relationship between the total number of hours outsourced and the total amount of labor (work hours) (Sánchez, Terlizzi, \& de Moraes, 2017). The community trust and technical teams emphasize planning to determine job to avoid performing unnecessary work. (Vahanvati, \& Mulligan, 2017). Setting project specification priorities make easier to estimate the necessary efforts for best performance (Vieira, Argoud, \& Antoniolli, 2017). To best understand work, processes split into tasks, and tasks divided into activities. Then, the measurement of pending action could be determined (Sánchez-Vicente, Soler-Severino, \& García-Santos, 2019).

\section{Backlog Preparation ordered list}

All work in the story for the team listed in sequence or priority (Agile Practice Guide, 2017). The product owner sets the task priorities (Azanha et al., 2017). Multiple versions of the epic (tasks) spreadsheet list misplacement happened because of its various versions (Dingsøyr, Moe, Seim, 2018). The contracts had a short list of requests to 'start doing,' instead of writing everything explicitly down, like in the construction projects (Lappi, Aaltonen, \& Kujala, 2018). The product owner prioritized the product backlog composed of the high-level user stories (Moe, Dingsøyr, \& Rolland, 2018). The product owner updated, perfected and reprioritize the product backlog with clear direction and in a more responsive way than before (Hobbs, \& Petit, 2017). The product owner was new in the prioritization of user stories in the backlog (Lappi, \& Aaltonen, 2017). Safe construction was first on the ordered list (Vahanvati, \& Mulligan, 2017). They had an initial list of requirements, but the estimation revisions were necessary along with the project performance (Vieira, Argoud, \& Antoniolli, 2017). Burn-up and burn-down charts were useful to plan and visualize the progress of work by the design team while supporting on the successive estimations of work and the distribution of its resources (Sánchez-Vicente, Soler-Severino, \& García-Santos, 2019).

\section{Backlog Refinement discussions}




\section{Issues in Information Systems \\ Volume 20, Issue 3, pp. 94-106, 2019}

Deliberations about how well work comply with the story requirements (Agile Practice Guide, 2017). The product owner and the team discussions were about task priorities and time completion (Azanha et al., 2017). Open workspace structure allowed for active engagement of the team discussions (Dingsøyr, Moe, Seim, 2018). Reviews were about the business case to align projects with potential suppliers (Lappi, Aaltonen, \& Kujala, 2018). Discussions were about both technical and business topics in an environment that fostered working in coordination (Moe, Dingsøyr, \& Rolland, 2018). To be more productive, team development, subcontractors, and other teams discussed customer requirements in person. However, they had to switch to virtual conferences, since the team's place of work was across the country (Lappi, \& Aaltonen, 2017). Discussions were about projects related to Information Technology infrastructure, business (cards, insurance, investments, and payments), legacy systems support, and regulatory issues and compliance (Terlizzi, Albertin, \& de Moraes, 2017). Deliverables in retail construction projects were the equivalent of 'user stories' in software development. Each deliverable split into activities (Sánchez-Vicente, Soler-Severino, \& García-Santos, 2019).

\section{Backlog Refinement meetings}

The product owner meets with the cross-functional team to present ideas for the stories and to learn about its potential challenges (Agile Practices Guide, 2017). Iteration planning meetings and 15-minutes daily standup meeting for reviewing what is needed to be productive, and regular feedback meetings (Azanha et al., 2017). It consisted mostly of demonstrations to customers (Dennehy, \& Conboy, 2018). Early in the project, many scheduled meetings, later many unscheduled meetings. Unscheduled virtual meetings were useful to receive help about technical questions without much interruption (Dingsøyr, Moe, Seim, 2018). The sessions consisted of workshops in which team members participated in the project arrangement, deliverable scoping, and procurement options (Lappi, Aaltonen, \& Kujala, 2018). There were structured and unstructured meetings. Tables and board were displayed to perform all the structured and informal sessions. Gatherings were also celebrated to discuss errors and to agree in correcting them (Moe, Dingsøyr, \& Rolland, 2018). The development teams celebrated daily standup meetings to comply with the Scrum methodology. The project team, the Scrum master, the product owner, and the development teams had meetings very frequently, at least, at the end of each sprint (Hobbs, \& Petit, 2017). Informal meetings are part of an agile project, while key people needed to be present in the formal sessions (Lappi, \& Aaltonen, 2017). Gatherings were celebrated to discuss and prioritize those projects with the highest Net Present Values (Terlizzi, Albertin, \& de Moraes, 2017). The community and the technical teams meet to discuss the benefits of building agility from the beginning while identifying construction challenges (Vahanvati, \& Mulligan, 2017). The agile context allowed team and client communication interactions in a pre-established frequency (Vieira, Argoud, \& Antoniolli, 2017).

\section{Backlog Refinement potential challenges}

Potential challenges focus on the selection of ideas of the stories (Agile Practices Guide, 2017). Integrating flow with existing processes, monitor instead of over-controlling, changing into a flow organization culture, using Kanban boards properly, establishing work time limits, calculating and interpreting flow in context, and tailored flow training (Dennehy, \& Conboy, 2018). The coordination among teams helped to avoid different groups to be working in the same coding (Dingsøyr, Moe, Seim, 2018). One challenge in the procurement was the confusion about the used terminology, and the agreement on the liabilities and insurance in the contract model (Lappi, Aaltonen, \& Kujala, 2018). In a large organization, the challenge was to work for internal and external customers (Hobbs, \& Petit, 2017). The trials were documentation, personnel education, stakeholder involvement, roles in an agile set-up, location of the agile teams, legislation, and the complexity of architecture and system integration (Lappi, \& Aaltonen, 2017). Lowering the cost may lead to prolonging the time of the project's completion (Sánchez, Terlizzi, \& de Moraes, 2017). There were delays in material delivery, and that measures of achievement focused on the on-going processes rather than on the overall project outcome (Vahanvati, \& Mulligan, 2017). Project challenges strengthen knowledge and experience (Vieira, Argoud, \& Antoniolli, 2017). The quality of deliverables was more critical than its speed performance while identifying exceptions where much quality does not bring value but compromises the date of delivery (Sánchez-Vicente, Soler-Severino, \& García-Santos, 2019).

\section{Backlog Refinement problems}

Issues were in understanding of the stories (Agile Practices Guide, 2017). To avoid misunderstanding, a 15-minutes stand-up daily same time and place meetings with the development team and the scrum master's presence optional (Azanha, et al., 2017). Trouble handling high-priority release at short time notice (Dennehy, \& Conboy, 2018). There was difficulty in finding the latest spreadsheet document containing the plan (Dingsøyr, Moe, Seim, 2018). A "bug board" was established for the team to solve technical and related issues. The scrum of scrums worked on solving complex problems, such as the interdependency across groups. Examples are security issues, integration of legacy systems, and performance issues (Moe, Dingsøyr, \& Rolland, 2018). The interpretation of the requirements of the projects represented a problem, as, the scope ambiguity. The business rules and its priorities were part of the conditions. The strategy adopted was to conduct pilot 


\section{Issues in Information Systems \\ Volume 20, Issue 3, pp. 94-106, 2019}

projects to isolate the requirements of the development process and the new role definitions (Hobbs, \& Petit, 2017). Documentation and systems integration needed improvements. They solved the issues by associating the skillful, innovative individuals and the strengths of the team. Effective communication was vital for gathering (Lappi, \& Aaltonen, 2017). There were unexpected problems in the software development process, such as misunderstood specifications, technical difficulties, inconclusive testing, and networking host related issues (Sánchez, Terlizzi, \& de Moraes, 2017). The intellectual property of documents was a concern while managing the project. Problems were related to understanding the difficulties by project teams daily, adapt the processes to the users' needs, and to justify the investment in process changes and training (Terlizzi, Albertin, \& de Moraes, 2017). It focuses on an inflexible timeframe for project completion, and only identifies technical challenges excluding other complex problems (Vahanvati, \& Mulligan, 2017). Costs varied due to the product quality, and the date of delivery. The organization had to define its procurement policies to avoid those cost variations. Cost estimations was a difficult task that sometimes leads to insufficient resources. The solution they found was to strengthen the information flow about cost and delivery time between the client and the provider. They developed parameters and metrics to do the estimations better (Vieira, Argoud, \& Antoniolli, 2017).

\section{Backlog Refinement story ideas}

Story ideas are the product owner's vision of what is needed (Agile Practice Guide, 2017). Story points are work items from their initial state into deployment, composed of eleven steps (Dennehy, \& Conboy, 2018). Many individual user stories with its sub-tasks wrote the epics or tasks (Dingsøyr, Moe, Seim, 2018). End users provided the stories and the validated deliverables (Lappi, Aaltonen, \& Kujala, 2018). The delivery model included a walkthrough of the release and the identification of high-level user stories (Moe, Dingsøyr, \& Rolland, 2018). The two (2) main story challenges were to manage a well-specified product sold under contract and when a customer made special requests (Hobbs, \& Petit, 2017). The product owner was new performing the task of clearly defining user stories or requirements on time (Lappi, \& Aaltonen, 2017). Deliverables in retail construction projects were the equivalent of 'user stories' in software development. Each deliverable split into activities (Sánchez-Vicente, Soler-Severino, \& García-Santos, 2019).

\section{Backlog Refinement value delivery}

The determination if the work produced is contributing to business value (Agile Practices Guide, 2017). Increased value to the product by the team every time the product backlog went from one sprint to the next, even though the significant issue was understanding customer value (Azanha et al., 2017). The team members need to take management standpoint of view to produce increased value to the customers (Dennehy, \& Conboy, 2018). The reward incentives did not emphasize the final product stage, but it was related to the actual deliveries and the value creation. This action improved the organizations' value delivery capability (Lappi, Aaltonen, \& Kujala, 2018). For value delivery, there were two main factors - first, the creation of a partnership between the customer's organization. Second, the role of the product owner (Hobbs, \& Petit, 2017). There is an incremental margin perspective between cost and time that influenced directly on the success of the project's scope (Sánchez, Terlizzi, \& de Moraes, 2017). The value delivery is determined after partial delivery or at the end of the project. Value indicators must be adequately established and formalized in the business case to be able to measure value delivery (Terlizzi, Albertin, \& de Moraes, 2017). Providing various material and technological choices were the value delivery which consisted of the socio-cultural principles (Vahanvati, \& Mulligan, 2017). For value delivery assurance, the user participation in validating and testing processes from the initial phase of the project to each of the stages was crucial. In agile, time was tide for delivery validations, including its documentation (Vieira, Argoud, \& Antoniolli, 2017). To measure value delivery, they did special activities to implement processes, to assign quantitative values to the effort (hours of work), and to determine the pending actions (Sánchez-Vicente, Soler-Severino, \& García-Santos, 2019).

\section{Team Composition product owner}

The product owner is responsible for guiding work while identifying its business value (Agile Practices Guide, 2017). The product owner defines the product backlog, list requirements, stipulates the task priorities with initial time estimation and some technical elements to be considered for best performance (Azanha et al., 2017). The product owner coordinate tasks according to teamwork achievements (Dingsøyr, Moe, Seim, 2018). The product owner represented the client representative within a development team and is responsible for the product definition and product acceptance (Lappi, Aaltonen, \& Kujala, 2018). The product owner prioritized the product backlog, consisting of the user stories. The product owner duties were to analyze of needs, the solution description, the construction of tested solutions, and the approval to verify if the release worked according to the expectations (Moe, Dingsøyr, \& Rolland, 2018). The product owner was known as the product manager. The product owner knew the differences between the agile culture and the organization's culture. The product owner represented the customer. The product owner had little business knowledge that slowed the decisions and the work. To avoid that situation, if the project was for internal operations, its product owner came from the same organization; 


\section{Issues in Information Systems \\ Volume 20, Issue 3, pp. 94-106, 2019}

otherwise, the product owner came from that other organization (Hobbs, \& Petit, 2017). Utilizing two product owners, one for the business requirement, and another one for the Information and Communication Technology caused problems with the agile team and the availability of information (Lappi, \& Aaltonen, 2017). The project owner is responsible for the performance of individual projects (Terlizzi, Albertin, \& de Moraes, 2017). The product owner was a local master artisan rather than external engineers who directed the work of a multidisciplinary team, including finance, social work, technical and artisanal backgrounds members (Vahanvati, \& Mulligan, 2017). The provider revised the team efforts to make sure the project is on time and as required (Vieira, Argoud, \& Antoniolli, 2017). The brand team acted as the product owner in this project (Sánchez-Vicente, Soler-Severino, \& García-Santos, 2019).

\section{Proposition}

We propose the embracing of the APM underpinnings, Backlog Refinement, Team Composition, and Backlog Preparation, as a strategy to successfully manage projects. The combination of both research objectives conducts this proposition. The RO 1 led to the identification of the underpinnings. The RO 2 led to the fact that organizations are implementing those underpinnings to transform their project management into agile. This proposition is the result of analyzing 168 items, which are the 14 APM elements, in Table 2, concerning the 12 cases that present APM element implementation, shown in Table 3.

\section{Recommendations}

Each agile project is unique. Therefore, applying agility may vary widely (Agile Practice Guide, 2017). Nonetheless, there must be an objective approach to discern what is essential when transforming project management into agile. The APM underpinnings are the main areas to emphasize in that transformation. We recommend using the APM underpinnings, as key in determining the effective adoption of agile in project management.

\section{Importance of the study}

This study is relevant to academy and companies because it explains the key areas to emphasize when transforming project management in to agile. The APM underpinning guide that transformation is strategical since those underpinnings align well with agile theories (Agile Manifesto Values, 2001) and organizations implement those underpinnings. While past studies from the 12 articles selected, Azanha, Argoud Terra, de Camargo Junior, \& Domingos Antoniolli (2017), Dennehy, \& Conboy (2018), Dingsøyr, Moe, Seim (2018), Hobbs, \& Petit (2017), Lappi, \& Aaltonen (2017), Lappi, Aaltonen, \& Kujala (2018), Moe, Dingsøyr, \& Rolland (2018), Sánchez-Vicente, Soler-Severino, \& García-Santos (2019), Sánchez, Terlizzi, \& de Moraes (2017), Terlizzi, Albertin, \& de Moraes (2017), Vahanvati, \& Mulligan (2017), and Vieira, Argoud, \& Antoniolli (2017), were informative in describing successful cases of APM, those did not explain agile best practices. Furthermore, the cases in the articles that we revised identified APG (2017) coverage with its element name or its description.

\section{CONCLUSIONS}

In conclusion, this study presents the agile project management underpinnings, according to the agile best practices, and discusses how organizations apply those underpinnings into their projects.

The RO 1 supported identifying the underpinnings, which are vital in transforming a project into agile. The RO 2 ascertained that organizations are starting to implement those underpinnings to transform their project management into agile. Twelve cases demonstrated how organizations are implementing those underpinnings through each of its element descriptions. The combination of both research objectives followed in proposing the adoption of the APM underpinnings, Backlog Refinement, Team Composition, and Backlog Preparation, as an approach to productively administer projects.

\section{Implications}

Agile projects aim to deliver business value. This study suggests that managers can trust the APM underpinnings to renew their projects into agile effectively. There are already other organizations implementing those underpinnings, as discovered in RO 2. 


\section{Issues in Information Systems}

Volume 20, Issue 3, pp. 94-106, 2019

\section{Limitations of the study}

We did an exhaustive work conducting two research objectives, the finding of APM underpinnings (RO 1), and its implementation in organizations (RO 2). Notwithstanding, the generalizations in the results of this study must be applied with caution because we only considered 12 cases to confirm the implementation of the APM underpinnings. It would have been better to find more case studies from other prestigious peer-reviewed journals, but our university library system only produced those.

\section{Directions for future research}

It would be interesting to perform RO 2 with additional case studies to find how other organizations are implementing the APM underpinnings. We need to document that kind of cases from different companies to have a wide variety of case studies. The higher the number of agile instances, the better it is to conduct relevant research in discovering new patterns in the APM area of knowledge for future studies. It would also be interesting to find out if other trustful sources had distill the essence of agile and if authoritative entities, such as the Agile Alliance, or the Project Management Institute, had crosschecked those results, and make them available to organizations.

\section{REFERENCES}

Agile Alliance, \& Project Management Institute. (2017). Agile practice guide (1st ed.). Newton Square, Pennsylvania: Project Management Institute, Inc. [Available at the Business Administration Library.]

Project Management Institute. (2017). A guide to the project management body of knowledge (PMBOK® Guide) (6 ${ }^{\text {th }}$ ed.). Newtown Square, Pennsylvania: Project Management Institute, Inc. [Available at the Business Administration Library.]

Microsoft Corporation. (2018). MS Access 2019 for Windows and MS Excel 2018, Redmond, Washington, United States: Microsoft Corporation.

Microsoft Corporation. (2019). MS Power BI 2019 Desktop, Redmond, Washington, United States: Microsoft Corporation.

The Shed (2019). The Shed commissions' original works of art, across all disciplines, for all audiences. New York, NY, The Bloomberg Building. Retrieved from https://theshed.org

Agile Manifesto (2001). Principles of Agile Manifesto. https://agilemanifesto.org/principles.html

Azanha, A., Argoud Terra, A. R., de Camargo Junior, J. B. D., \& Domingos Antoniolli, P. (2017). APM with Scrum. International Journal of Managing Projects in Business, 10(1), 121-142. https://doi.org/10.1108/ijmpb-06-2016-0054

Dennehy, D., \& Conboy, K. (2018). Identifying Challenges and a Research Agenda for Flow in Software Project Management. Project Management Journal, 49(6), 103-118. https://doi.org/10.1177/8

Dingsøyr, T., Moe, N. B., \& Seim, E. A. (2018). Coordinating Knowledge Work in Multiteam Programs: Findings From a Large-Scale Agile Development Program. Project Management Journal, 49(6), 64-77. https://doi.org/10.1177/8756972818798980

Hobbs, B., \& Petit, Y. (2017). Agile Methods on Large Projects in Large Organizations. Project Management Journal, 48(3), 3-19. https://doi.org/10.1177/875697281704800301

Lappi, T. M., Aaltonen, K., \& Kujala, J. (2018). The birth of an ICT project alliance. International Journal of Managing Projects in Business, O(0). https://doi.org/10.1108/IJMPB-02-2018-0036

Lappi, T., \& Aaltonen, K. (2017). Project governance in public sector agile software projects. International Journal of Managing Projects in Business, 10(2), 263-294. https://doi.org/10.1108/IJMPB-04-2016-0031

Moe, N. B., Dingsøyr, T., \& Rolland, K. (2018). To schedule or not to schedule? An investigation of meetings as an inter-team coordination mechanism in large-scale agile software development. International Journal of Information Systems and Project Management, 6(3), 45-59. https://doi.org/10.12821/ijispm060303 


\section{Issues in Information Systems}

Volume 20, Issue 3, pp. 94-106, 2019

Sánchez, O. P., Terlizzi, M. A., \& de Moraes, H. R. de O. C. (2017). Cost and time project management success factors for information systems development projects. International Journal of Project Management, 35(8), 1608-1626. https://doi.org/10.1016/j.ijproman.2017.09.007

Sánchez-Vicente, H., Soler-Severino, M., \& Garcia-Santos, A. (2019). Estimation of Speed in Design Teams. The Journal of Modern Project Management, 6(3), 143-155. https://doi.org/10.19255/JMPM01809

Terlizzi, M. A., Albertin, A. L., \& de Moraes, H. R. de O. C. (2017). IT benefits management in financial institutions: Practices and barriers. International Journal of Project Management, 35(5), 763-782. https://doi.org/10.1016/j.ijproman.2017.03.006

Vahanvati, M., \& Mulligan, M. (2017). A new model for effective post-disaster housing reconstruction: Lessons from Gujarat and Bihar in India. International Journal of Project Management, 35(5), 802-817. https://doi.org/10.1016/j.ijproman.2017.02.002

Vieira, G. L. S., Argoud, A. R. T. T., \& Antoniolli, P. D. (2017). Cost And Time Estimates During The Supplier Selection Of An Information System For Legal Area: A Case Study Comparing Traditional And Agile Project Approaches. Iberoamerican Journal of Project Management, 8(1), 20-48. 